\title{
Studies on Biochemical and Mineral Profile of Anestrus Murrah Buffaloes Treated with Different Hormonal Protocols
}

\author{
Kumar Rohit ${ }^{1}$, Sinha, Manoranjan Prasad ${ }^{1}$ and Prasad Raju ${ }^{2 *}$ \\ ${ }^{1}$ Department of Veterinary Gynaecology and Obstetrics, ${ }^{2}$ Department of Veterinary \\ Pharmacology and Toxicology, College of Veterinary Science and Animal Husbandry, BAU, \\ Kanke, Ranchi-834 006, Jharkhand, India \\ *Corresponding author
}

\section{A B S T R A C T}

\begin{tabular}{|l|}
\hline Ke y w o r d s \\
$\begin{array}{l}\text { Biochemical, Mineral } \\
\text { profile, Anestrus Murrah } \\
\text { buffaloes, Hormonal } \\
\text { protocols }\end{array}$ \\
\hline Article Info \\
\hline $\begin{array}{l}\text { Accepted: } \\
\text { 10 September } 2018 \\
\text { Available Online: } \\
\text { 10 October } 2018\end{array}$ \\
\hline
\end{tabular}

\section{Introduction}

Alterations in various biochemical constituents are responsible for reproductive failures (Prabha et al., 2000). Cholesterol is the most important sterol and is the essential precursor for steroid hormone synthesis controlling reproduction. Minerals also play an important role in regulation of reproction and production in animals. Lower concentration of circulatory minerals mainly $\mathrm{Ca}, \mathrm{P}$ and $\mathrm{Mg}$ results in impaired reproductive function leading to cessation of cyclic activity (Martson et al., 1972). Micronutrients also play a vital role in the control of reproduction.
The minerals like calcium and phosphorous are very important in animal production and reproduction. Calcium and phosphorous play intermediate role in the action of reproductive hormones and enzymes at a sub cellular level in an integrated fashion in the initiation of estrus in animals (Ali et al., 1991). Rogers (1992) opined that the imbalance or deficiency of trace elements $(\mathrm{Zn}, \mathrm{Cu}$, etc.) leads to inactive ovaries and repeat breeding in dairy animals.

This study was planned to study the biochemical and mineral changes due to two different hormonal treatment protocols in anestrus Murrah buffaloes. 


\section{Materials and Methods}

The study was conducted on Eighteen Indian buffaloes (age: 3-6 years) reared at Instructional dairy farm, Ranchi Veterinary College, Kanke and local khatals near Kanke, Ranchi. Animals with smooth and quiescent ovaries were identified. The selected animals were allotted to 3 groups consisting of 6 animals in each group and subjected to the therapeutic management as per the following protocol.

Group-I: CIDR (controlled internal drug release) Protocol $(n=6)$, an intra-vaginal device $(0.96 \mathrm{~g}$ hydroxyprogesterone in elastic rubber molded over a nylon spine) was inserted into vagina with the help of the applicator and was kept in situ for 7 days. The CIDR device was removed on $7^{\text {th }}$ day and $2 \mathrm{ml}$ of PGF2 $\alpha$ (Cloprostenol I.P $263 \mu \mathrm{g}$ ) was injected I.M. on the $7^{\text {th }}$ day after removal of CIDR device. Fixed Time Artificial Insemination (FTAI) was done with frozen thawed semen $48 \mathrm{hrs}$ after the withdrawal of the device.

Group-II: Ovsynch Protocol $(\mathrm{n}=6)$, The animals of this group was treated under Ovsynch protocol where $5 \mathrm{ml} \mathrm{GnRH}$ analogue (Buserelin IP $-0.004 \mathrm{mg}$ ) was injected I.M to each animal on day 0 followed by $2 \mathrm{ml} \mathrm{PGF} 2 \alpha$ analogue (Cloprostenol IP $263 \mu \mathrm{g}$ ) on day $7^{\text {th }}$, again on day 9th $5 \mathrm{ml}$ of $\mathrm{GnRH}$ analogue was injected and all the animals were inseminated with frozen semen after $24 \mathrm{hrs}$ (FTAI) on 10th day.

Group-III: Anestrus Control ( $\mathrm{n}=6$ ) six normal but acyclic buffaloes each were injected with normal saline; $5 \mathrm{ml}, \mathrm{i} / \mathrm{m}$ on days 0 and 9 . They were followed for onset of natural estrus and insemination. Specimen numbers of hormonally treated true anestrus buffaloes were studied for their nutritional status. For this, jugular blood samples approximately $5 \mathrm{ml}$ were collected in slanting test-tubes four times from true anestrus buffaloes among groups. i.e., on day 0 - just before start of treatment, on day 7 just before PGF2 $\alpha$ administration, on day $9 / 10$ (day of A.I) and day $60^{\text {th }}$ post treatment. The serum samples were centrifuged at $2500 \mathrm{rpm}$ for 15 minutes, and serum separated out was transferred to $4.5 \mathrm{ml}$ storage vials and stored in deep freeze at $20^{\circ} \mathrm{Cwith}$ a drop of Merthiolate $(0.1 \%)$, as preservative until analyzed.

\section{Results and Discussion}

During the present study the overall cholesterol level up to 60 days were obtained to be $65.82,63.19$, and $61.15 \mathrm{mg} / \mathrm{dl}$ in CIDR, Ovsynch and Control group anestrus buffaloes respectively. Buhechha et al., (2016b) recorded relatively higher plasma cholesterol level in anestrus buffaloes under same protocol while comparatively much lower values were recorded by Parmar (2013) and Nakrani et al., (2014b). This may be due to differences in the nutritional statuses of animals and the assay kits and procedures followed. The higher level of cholesterol in animals may be attributed to the effect of $\mathrm{GnRH}$, which is said to have influence on lipoprotein metabolism in a positive manner (Kumari et al., 2015). Slightly lower concentration of cholesterol observed both in CIDR treated buffaloes and Ovsynch protocol group animals on day $0,7,9 / 10$ suggested that cholesterol might have been utilized in the steroidal hormone synthesis.

In the present study, at all days/period mean cholesterol concentration was nonsignificantly higher in conceived than nonconceived animals for both CIDR and Ovsynch groups. These results between conceived buffaloes under both protocols are in line with the earlier observation of Savalia et al., (2014), Nakrani et al., (2014b) and Shivajibhai (2016). Plasma calcium values neither varied significantly between sampling days, within protocol nor between the 
protocols. The non-significant variation in plasma calcium level was also recorded between conceived and non-conceived buffaloes in all three treatment groups. The present observations of non-significant variation between sampling days within the protocol and or between the protocol are comparable with the recent studies documented by some of the workers using Ovsynch and CIDR in buffaloes (Savalia et al., 2013 and Shivajibhai, 2016). In contrast, Buhecha et al., 2016 reported significantly higher plasma Calcium concentration under CIDR protocol as compared to the values of other treatment groups. However, the calcium level obtained in the present study are within normal range as reported by various authors in cyclic and non-cyclic anestrus buffaloes (Ali et al., 2012b and Shivajibhai, 2016). The concentration of calcium in the body fluids depends on the mineral contents of the feed and forage, the level of dietary sources intake and the availability of minerals (Suttle, 2010). This indicates a direct plant-animal relationship. The altered Ca: $\mathrm{P}$ ratio may affect ovarian function through its blocking action on pituitary gland, which results in prolongation of first oestrus and ovulation ultimately reducing the reproduction efficiency (Satish kumar, 2003). The levels of plasma phosphorous neither varied significantly between sampling days in any of treatment protocol nor between conceived and non-conceived buffaloes in any group. The present findings are in coroboration with the report of Shivaji bhai (2016) in cases of buffaloes after CIDR/Ovsynch protocol. However comparatively lower values have been reported by some workers using CIDR and Ovsynch protocol in anestrus buffaloes including normal cyclic groups (Savalia et al., 2013, Nakrani et al., 2014 and Buheacha et al., 2016b). Bhaskaran and Ichaa (1981) documented that the marginal deficiency of phosphorous is enough to cause disturbance in pituitary-ovarian-axis. Butani et al., (2011) and Savalia et al., (2013) did not find variation in the mean plasma phosphorous levels on day of GnRH and PG treatment at induced oestrus and on day 21 post AI in anoestrus or suboestrus buffaloes which also supports the present findings.

The plasma magnesium concentration neither varied significantly between sampling days nor between the treatment groups. The value also didn't vary significantly between conceived and non-conceived animals within the group under any protocol. Similar trend was reported by Savalia et al., (2013) and Shivaji bhai (2016) in Ovsynch and CIDR group. The present non-significant differences observed in plasma magnesium profile on different dates of sampling corroborated with the reports of Sharma et al., (1999) in Murrah buffaloes, Paul et al., (2000) Nilli-Ravi buffaloes, and Butani et al., (2011) in Surti buffaloes. Latif et al., (1993) and Newer et al., (1999) reported the non- significant difference in the mean plasma magnesium levels between cyclic and anestrus animals in Mehsana and Swamp buffaloes, respectively. The imbalance of other minerals such as calcium, phosphorus and potassium may decrease magnesium absorption from the gut of ruminants.

The levels of Plasma Copper content recorded on day $0,7,9 / 10$ and day 60 in CIDR group, Ovsynch group and Control group were estimated. No significant difference was observed within days in these groups with respect to copper content. The mean plasma Copper content in conceived and nonconceived groups in all the three experimental groups were also found to be statistically similar and non-significant on day $0,7,9 / 10$ and 60. The influence of estrus induction protocols like CIDR and Ovsynch on Copper levels in buffaloes could not be seen in literature reviewed (Table 1). 
Table.1 Plasma biochemical and mineral profile in different days of sampling of anestrus buffaloes treated with CIDR and Ovsynch protocol (Mean \pm S.E)

\begin{tabular}{|c|c|c|c|c|c|c|c|}
\hline \multirow{2}{*}{$\begin{array}{l}\text { Biochemical } \\
\text { and Mineral } \\
\text { Profiles }\end{array}$} & \multirow{2}{*}{$\begin{array}{l}\text { Group/ } \\
\text { Estrus } \\
\text { induction } \\
\text { protocol }\end{array}$} & \multicolumn{5}{|c|}{ Different days of the treatment } & \multirow[t]{2}{*}{ Average Value } \\
\hline & & $\mathbf{N}$ & Day 0 & Day 7 & Day $9 / 10$ & Day 60 & \\
\hline \multirow{3}{*}{ Cholesterol } & CIDR & 6 & $63.18 \pm 1.26$ & $65.41 \pm 1.44$ & $66.25 \pm 1.37$ & $68.43 \pm 2.02$ & $65.82 \pm 0.82^{\mathrm{a}}$ \\
\hline & Ovsynch & 6 & $60.00 \pm 1.11$ & $62.62 \pm 1.82$ & $63.67 \pm 1.88$ & $66.47 \pm 1.74$ & $63.19 \pm 1.00^{b}$ \\
\hline & Control & 6 & $60.23 \pm 1.81$ & $60.18 \pm 1.99$ & $61.22 \pm 1.36$ & $62.95 \pm 1.59$ & $61.15 \pm 0.85^{b}$ \\
\hline \multirow{3}{*}{ Calcium } & CIDR & 6 & $8.35 \pm 0.11$ & $8.43 \pm 0.22$ & $8.45 \pm 0.13$ & $8.54 \pm 0.16$ & $8.44 \pm 0.08$ \\
\hline & Ovsynch & 6 & $8.15 \pm 0.05$ & $8.48 \pm 0.26$ & $8.33 \pm 0.09$ & $8.49 \pm 0.11$ & $8.37 \pm 0.05$ \\
\hline & Control & 6 & $8.15 \pm 0.12$ & $8.22 \pm 0.11$ & $8.42 \pm 0.15$ & $8.55 \pm 0.14$ & $8.33 \pm 0.07$ \\
\hline \multirow{3}{*}{ Phosphorous } & CIDR & 6 & $5.11 \pm 0.03$ & $5.13 \pm 0.05$ & $5.12 \pm 0.04$ & $5.12 \pm 0.10$ & $5.12 \pm 0.03$ \\
\hline & Ovsynch & 6 & $5.24 \pm 0.05$ & $5.32 \pm 0.05$ & $5.07 \pm 0.04$ & $4.71 \pm 0.17$ & $5.08 \pm 0.07$ \\
\hline & Control & 6 & $4.76 \pm 0.30$ & $4.68 \pm 0.28$ & $4.86 \pm 0.26$ & $4.81 \pm 0.26$ & $4.78 \pm 0.13$ \\
\hline \multirow{3}{*}{ Magnesium } & CIDR & 6 & $2.06 \pm 0.05$ & $2.24 \pm 0.14$ & $2.28 \pm 0.28$ & $2.28 \pm 0.32$ & $2.21 \pm 0.04$ \\
\hline & Ovsynch & 6 & $2.13 \pm 0.16$ & $2.19 \pm 0.16$ & $2.27 \pm 0.24$ & $2.32 \pm 0.23$ & $2.22 \pm 0.03$ \\
\hline & Control & 6 & $2.33 \pm 0.21$ & $2.30 \pm 0.18$ & $2.20 \pm 0.19$ & $2.16 \pm 0.13$ & $2.25 \pm 0.09$ \\
\hline \multirow{3}{*}{ Copper } & CIDR & 6 & $0.39 \pm 0.05$ & $0.41 \pm 0.06$ & $0.43 \pm 0.12$ & $0.46 \pm 0.05$ & $0.42 \pm 0.02$ \\
\hline & Ovsynch & 6 & $0.38 \pm 0.01$ & $0.43 \pm 0.01$ & $0.39 \pm 0.01$ & $0.43 \pm 0.01$ & $0.41 \pm 0.01$ \\
\hline & Control & 6 & $0.42 \pm 0.02$ & $0.42 \pm 0.01$ & $0.43 \pm 0.01$ & $0.48 \pm 0.01$ & $0.44 \pm 0.01$ \\
\hline
\end{tabular}

Same superscript did not differs significantly with the column

However, the level of copper estimated during the present study was near the normal serum copper concentration (0.5-1.0 ppm) studied under different physiological conditions under farm conditions (Geogievskii, 1982). Copper is an essential trace element for normal reproduction performance of the buffaloes and deficiency of copper is generally accompanied by anemia, debility and lack of appetite and also results in failure of estrus and delayed onset of puberty (Underwood, 1981). It indicates that the reproductive problems may be associated with the reduced copper level in animals.

\section{Acknowledgement}

The authors are thankful to the Dean, College of Veterinary Science and Animal Husbandry, Kanke, Ranchi for providing necessary facilities.
On the basis of above result, it can be concluded that none of the hormonal protocol had any significant effect on blood biochemical and mineral profiles on any day of sampling.

\section{References}

Ali, M. D. M., Kanjilal, B.C., Roychoudhari, R., Bandopadhya, S.K. and Ghosh, B.B. (1991) Total serum protein and Hemoglobin content in anestrus rural crossbred heifers. Indian J. Anim. Reprod. 12(2): 159-161

Ali, R., Shukla, S.P., Nema, S.P. and Mudasir, Q. (2012b). Biochemical changes in post- partum anoestrus buffaloes treated with Ovsynch, Heatsynch and CIDR hormone protocols. Veterinary Practitioner 13(1): 41-42. 
Bhaskaran, R. and Abdulla Khan, C.K. (1981). Role of blood serum inorganic phosphorus in postparturient anoestrus cows. Livestock Adviser, 9(6): 33-36.

Buhecha, K.V., Dhami, A.J., Patel, M.D., Hadiya, K.K., Shah, R.G. and Kharadi, V.B. (2016a). Study on different oestrus induction protocols with respect to fertility and plasma progesterone profile in anoestrus buffaloes. Indian J. Dairy Sci., 69(2): 197-201.

Buhecha, K.V., Dhami, A.J., Theodore, V.K., Thakor, R. and Parmar, S.C. (2016b). Effect of various ovulation synchronization protocols on oestrus response, conception rate and blood biochemical profile in anoestrus buffaloes. International J. Adv. Vet. Sci. and Technol., 5(1): 232-238.

Butani, M.G., Dhami A.J. and Rajesh Kumar (2011). Comparative blood profile of progesterone, metabolites and minerals in anoestrus, suboestrus, repeat breeding and normal cyclic buffaloes. Indian $\mathrm{J}$. Field Vets., 7(2): 20-24.

Georgievskii, V.I. (1982). Mineral composition of bodies and tissue of animals, p. 67-77. In Georgievskii V.I., B.N. Annenkov and V. T. Samokhin (eds.) Mineral Nutrition of Animals. Butterworths, London, England.

Kumar, A., C. Singh and A.P. Singh (2002). Effect of feeding mineral mixture on plasma manganese concentration in cattle. Indian J. Anim. Sci., 72: 510-12.

Kumari, K., Mishra, U. K., Kumar, K., Praveen, P.K., Dalai, N. and Shekhar, S. (2015). Changes in serum biochemical parameters before and after Ovsynch treatment in Murrah buffaloes. J. Cell and Tissue Res., 15(1): 4833-4837.

Latif, A., Siddiquee, G.M. and Vadodaria, V.P. (1993). Biochemical studies on postpartum anoestrus in Mehsani buffaloes. Indian J. Anim. Reprod., 14(1): 64 .
Mortson, H.R., Allen, J.H. and Smith R.M. (1972). Role of minerals in reproduction. British J. Nutri., 27:127

Nakrani, B.B., Panchal, M.T., Dhami, A.J., Hadiya, K.K., Patel, J.A., Gosai, R.K. and Shah R.G. (2014a). Influence of controlled breeding techniques on oestrus induction response, conception rate and plasma progesterone profile in anoestrus buffaloes. Global J. Med. Res., 14(3): 1-6.

Nakrani, B.B., Panchal, M.T., Dhami, A.J., Hadiya, K.K., Patel, J.A. and Gosai, R.K. (2014b). Effect of controlled breeding techniques on fertility and plasma profile of biochemical and mineral constituents in anoestrus buffaloes. Scholars J. Agric. Vet. Sci., 1(4B): 299-304.

Newer, S., Baruah, K.K., Baruah, A., Bhuya, D. and Kalita, D.J. (1999). Studies on certain macro mineral status in anoestrus and cyclic postpartum swamp buffaloes. Indian Vet. J., 76(7): 871872.

Parmar, B.N. (2013). Augmenting reproductive efficiency of infertile buffaloes using controlled breeding techniques in tribal areas. MVSc Thesis, Anand Agricultural University, Anand, Gujarat, India.

Paul, S.S., Chawla, D.S. and Lall, D. (2000). Serum mineral profile and its relationship with reproductive disorders in Nili-Ravi buffaloes. Indian J. Anim. Nutri., 17(4): 324-327.

Prabha, B., Singh, C., Murtaza, M., and Pandey, R.P. (2000). Total serum inorganic phosphorus concentration in crossbred (Friesian X Hariana) pregnant cows and calves. Indian J. Anim. Sci. 70:50-51

Satish Kumar (2003). Management of infertility due to mineral deficiency in dairy animals. In: Proceedings of ICAR summer school on "Advance diagnostic 
techniques and therapeutic approaches to metabolic and deficiency diseases in dairy animals" held at IVRI, Izatnagar, UP (15th July to 4th Aug.). pp. 128137.

Savalia, K.K., Dhami, A.J., Hadiya, K.K., Patel, K.R. and Sarvaiya, N.P. (2014). Influence of controlled breeding techniques on fertility and plasma progesterone, protein and cholesterol profile in true anoestrus andrepeat breeding buffaloes. Veterinary World, 7(9): 727-732. DOI: 10.14202/vetwold. 2014.727-732.

Savalia, K.K., Dhami, A.J., Patel, K.R. and Hadiya, K.K. (2013). Influence of controlled breeding techniques on fertility and plasma macro-minerals profile in conceiving and nonconceiving anoestrus and repeat breeding buffaloes. Indian J. Field Vet., 9(2): 28-35.

Sharma, K.B., Shashi Nayyar; V.S. Malik; Singh, Ravir and S.P.S. Sodhi (1999): Level of hormones and minerals in cyclic, anoestrus and sub-oestrus buffalo heifers. Int.J.Anim.Sci., 69(4):214-216.

Shivajibhai, M.K. (2016). Seasonal influence on efficacy of oestrus induction and synchronization protocols in anoestrus buffaloes. M.V.Sc. Thesis, College Of Veterinary Science and Animal Husbandry, Anand Agricultural University Anand, India.

Suttle, N.F. (2010). Mineral Nutrition of Livestock. 4th ed, Midlothian, UK.

Underwood, E.J. (1981). The Mineral Nutrition of Livestock, 2nd ed. Commonwealth Agricultural Bureaux, U.K.

\section{How to cite this article:}

Kumar Rohit, Sinha, Manoranjan Prasad and Prasad Raju. 2018. Studies on Biochemical and Mineral Profile of Anestrus Murrah Buffaloes Treated with Different Hormonal Protocols. Int.J.Curr.Microbiol.App.Sci. 7(10): 1010-1015. doi: https://doi.org/10.20546/ijcmas.2018.710.112 